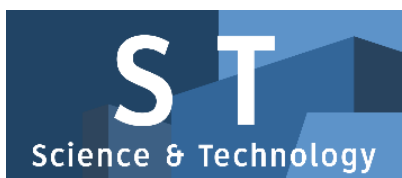

PAPER - OPEN ACCESS

\title{
Analisis Karakteristik Fungsi Lagrange Dalam Menyelesaikan Permasalahan Optimasi Berkendala
}

\author{
Author \\ : Theresia Mehwani Manik \\ DOI \\ : 10.32734/st.v1i1.187 \\ Electronic ISSN \\ : 2654-7089 \\ Print ISSN \\ : 2654-7081
}

Volume 1 Issue 1 - 2018 TALENTA Conference Series: Science \& Technology (ST)

\section{(a) $(1) \Theta$}

This work is licensed under a Creative Commons Attribution-NoDerivatives 4.0 International License.

Published under licence by TALENTA Publisher, Universitas Sumatera Utara
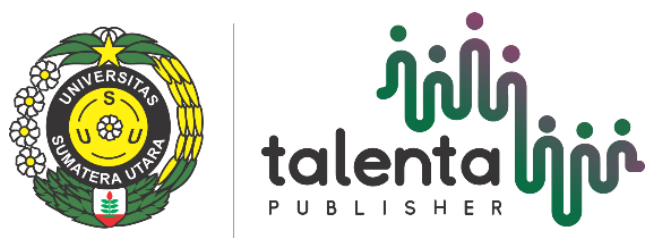


\title{
jiji talentalioำ TALENTA Conference Series \\ P U B L I S H E R Available online at https://talentaconfseries.usu.ac.id \\ Analisis Karakteristik Fungsi Lagrange Dalam Menyelesaikan Permasalahan Optimasi Berkendala
}

\author{
Theresia Mehwani Manik ${ }^{\mathrm{a}^{*}}$, Parapat Gultom ${ }^{\mathrm{a}}$, Esther Nababan ${ }^{\mathrm{a}}$ \\ Departemen Matematika, FMIPA, Universitas Sumatera Utara, Medan-20155
}

theresiamehwanimanik@gmail.com

\begin{abstract}
Abstrak
Optimasi adalah suatu aktivitas untuk mendapatkan hasil terbaik di dalam suatu keadaan yang diberikan. Tujuan akhir dari aktivitas tersebut adalah meminimumkan usaha (effort) atau memaksimumkan manfaat (benefit) yang diinginkan. Metode pengali Lagrange merupakan metode yang digunakan untuk menangani permasalahan optimasi berkendala. Pada penelitian ini dianalisis karakteristik dari metode pengali Lagrange sehingga metode ini dapat menyelesaikan permasalahan optimasi berkendala. Metode tersebut diaplikasikan pada salah satu contoh optimasi berkendala untuk meminimumkan fungsi objektif kuadrat sehingga diperolehlah nilai minimum dari fungsi objektif kuadrat adalah -0.0403. Banyak masalah optimasi tidak dapat diselesaikan dikarenakan kendala yang membatasi fungsi objektif. Salah satu karakteristik dari metode pengali Lagrange adalah dapat mentransformasi persoalan optimasi berkendala menjadi persoalan optimasi tanpa kendala. Dengan demikian persoalan optimasi dapat diselesaikan.
\end{abstract}

Kata Kunci; Optimasi, Optimasi Berkendala, Metode Pengali Lagrange

\section{Pendahuluan}

Optimasi (Optimization) adalah aktivitas untuk mendapatkan hasil terbaik di dalam suatu keadaan yang diberikan. Tujuan akhir dari aktivitas tersebut adalah meminimumkan usaha (effort) atau memaksimumkan manfaat (benefit) yang diinginkan. Karena usaha yang diperlukan atau manfaat yang diinginkan dapat dinyatakan sebagai proses untuk menemukan kondisi yang memberikan nilai minimum atau maksimum dari sebuah fungsi. Kondisi tersebut dapat dimodelkan dalam fungsi tujuan, dimana fungsi tujuan itu dapat berupa fungsi linier atau fungsi non linier.

Dalam menyelesaikan permasalahan optimasi terdapat dua kondisi yaitu optimasi tanpa kendala dan optimasi dengan kendala.Salah satu metode yang digunakan untuk menyelesaikan masalah optimasi dengan kendala adalah metode subsitusi. Namun demikian, metode ini hanya dapat digunakan pada masalah optimasi dengan kendala persamaan.Tetapi metode ini tidak selalu membawa hasil bilamana kendalanya melibatkan lebih dari satu persamaan kendala. Sedangkan masalah optimasi dengan kendala sering muncul dalam masalah nyata, dimana kendalanya tidak hanya satu fungsi. Hal ini mengakibatkan tidak mudah untuk menyederhanakan masalah. Tidak ada metode tunggal yang dapat dipakai untuk menyelesaikan semua masalah optimasi. Banyak metode optimasi telah dikembangkan untuk menyelesaikan tipe optimasi yang berbeda-beda.

Salah satu metode untuk mengatasi masalah optimasi dengan kendala adalah metode pengali Lagrange. Metode pengali Lagrange (Lagrange multiplier) dikemukakan oleh Joseph Louis Lagrange (1736-1813). Metode ini dilakukan dengan mentransformasi persoalan optimasi berkendala menjadi persoalan optimasi tanpa kendala, selain itu metode ini juga dapat menyelesaikan masalah dengan fungsi persamaan atau pertidaksamaan yang dimuat pada fungsi objektif atau pada fungsi kendalanya. Tujuan penelitian ini adalah menganalisis karakteristik dari Metode Pengali Lagrange dalam menyelesaikan permasalahan optimasi berkendala. 


\section{Landasan Teori}

Optimasi (Optimization) adalah aktivitas untuk mendapatkan hasil terbaik di bawah keadaan yang diberikan. Tujuan akhir dari semua aktivitas tersebut adalah meminimumkan usaha (effort) atau memaksimumkan manfaat (benefit) yang diinginkan. Permasalahan optimasi dapat dibagi menjadi dua kondisi yaitu optimasi tanpa kendala dan optimasi dengan kendala.

- Optimasi Tanpa Kendala

Masalah optimasi yang tidak melibatkan sebarang kendala dinamakan optimasi tanpa kendala dan dinyatakan sebagai: Maksimum/Mininimum

$$
\begin{gathered}
f=f(X) \\
X=\left(x_{1}, x_{2}, \ldots, x_{n}\right)^{T}
\end{gathered}
$$

- Optimasi Dengan Kendala

Masalah optimasi yang melibatkan sebarang kendala dinamakan optimasi terkendala dan dinyatakan sebagai: Maksimum/Mininimum

$$
\begin{aligned}
& f=f(X) \\
& X=\left(x_{1}, x_{2}, \ldots, x_{n}\right)^{T}
\end{aligned}
$$

Dengan kendala: $\quad g_{i}(X) \leq 0 \quad i=1,2, \ldots, m$

$$
l_{j}(X)=0 \quad j=1,2, \ldots, p
$$

Di mana $X$ adalah sebuah vektor berdimensi- $n$ yang dinamakan vektor disain atau variabel keputusan, $f(X)$ disebut fungsi obyektif, gi $X$ dan $l j X$ dikenal sebagai kendala ketaksamaan dan kendala kesamaan (P. Moengin, 2011).

\subsection{Perumusan Masalah Optimasi}

Metode pencari titik optimum juga dikenal sebagai teknik pemrograman matematikal dan menjadi bagian dari penelitian operasional (operations research). Penelitian operasional adalah suatu cabang matematika yang menekankan kepada aplikasi teknik dan metode saintifik untuk masalah-masalah pengambilan keputusan dan pencarian solusi terbaik atau optimal. Teknik pemrograman matematikal sangat berguna dalam pencarian minimum suatu fungsi beberapa variabel di bawa kendala yang ada. Optimasi atau masalah pemrograman matematika dapat dinyatakan sebagai berikut.

Tabel 1. Metode Penelitian Operasional

\begin{tabular}{lll}
\hline Teknik Pemrograman Matematikal & Teknik Proses Stokastik & Metode Statistikal \\
\hline Metode Kalkulus & Teori Keputusan & Analisis Regresi \\
Pemrograman Geometrik & Proses Markov & Analisis Kluster, Pattern \\
Pemrograman Nonlinier & Teori Antrian & Recognition \\
Pemrograman Kuadrati k & Renewal Theory & Rancangan Eksperimen \\
Pemrograman Linier & Simulasi & Analisis Diskriminan \\
Pemrograman Dinamik & & \\
Pemrograman Integer & Reliability Theory & \\
Pemrograman Stokastik & & \\
Pemrograman Seperable & & \\
Pemrograman Multiobyektif & & \\
Metode Jaringan : CPM \& PERT & &
\end{tabular}


Teori Permainan

Simulated Annealing

Genetic Algorithm

Neural Networks

\subsection{Maksimum Dan Minimum}

\subsubsection{Teorema keberadaan Maksimum-Minimum}

Jika $f$ kontinu pada sebuah himpunan $S$ tertutup terbatas, maka $f$ mencapai nilai maksimum (global) dan nilai minimum (global) di himpunan tersebut.

Misalkan $f$ adalah fungsi dengan daerah asal $S$, dan misalkan $\boldsymbol{p} 0$ adalah sebuah titik di $S$.

1. $(\boldsymbol{p} 0)$ adalah nilai maksimum global dari $f$ di $S$ jika $(\boldsymbol{p} 0) \geqslant(\boldsymbol{p})$ untuk seluruh $\boldsymbol{p}$ di $S$.

2. $\quad(\boldsymbol{p} 0)$ adalah nilai maksimum global dari $f$ di $S$ jika $(\boldsymbol{p} 0) \leqslant(\boldsymbol{p})$ untuk seluruh $\boldsymbol{p}$ di $S$.

3. ( $(\boldsymbol{p} 0)$ adalah nilai ekstrem global dari $f$ di $S$ jika $(\boldsymbol{p} 0)$ bukan nilai maksimum global dan bukan nilai minimum global.

Untuk menentukan nilai ekstrem fungsi adalah dengan menentukan titik di daerah asal fungsi, sedemikian sehingga $f$ mencapai nilai maksimum atau minimum. Titik-titik demikian disebut dengan titik kritis (Purcell, E.J., Dale, V., and Steven, E.R. 2003).

\subsubsection{Teorema Titik Kritis}

Misalkan $f$ didefinisikan pada sebuah himpunan $S$ yang mengandung $\boldsymbol{p} 0$. Jika ( $\boldsymbol{p} 0)$ adalah sebuah nilai ekstrem, maka $\boldsymbol{p} 0$ harus merupakan sebuah titik kritis, yaitu $\boldsymbol{p} 0$ adalah

i. Sebuah titik batas di $S$

ii. Sebuah titik stasioner dari $f$

iii. Sebuah titik tunggal dari $f$

Dari definisi di atas, menyatakan bahwa syarat perlu agar fungsi dua variabel mempunyai nilai ekstrim adalah adanya titik kritis. Titik kritis yang dibahas dalam hal ini adalah titik stasioner.

\subsubsection{Titik Stasioner - Uji Turunan Pertama}

Titik $(x 0, y 0)$ dikatakan sebagai titik stasioner pada daerah asal fungsi $f$ bilamana, $f x x 0, y 0=0$ dan $f y x 0, y 0=0$

Definisi di atas, menyatakan bahwa syarat perlu adanya nilai ekstrem fungsi dua variabel adalah fungsi

$f$ mempunyai turunan parsial pertama, dan adanya titik yang memenuhi turunan pertama sedemikian sehingga nilainya nol.

\subsubsection{Uji Turunan Kedua}

Andaikan $(x, y)$ mempunyai turunan parsial kedua kontinu dalam daerah $(x 0, y 0)$ dimana $f x x 0, y 0=0$ dan $f y x 0, y 0$ $=0$. Misalkan,

$$
\begin{array}{ll}
D=(x 0, y 0)=f x x x 0, y 0 f y y x 0, y 0-[f x y(x 0, y 0)] 2 \\
\text { i. } & \text { Jika } D>0 \text { dan } f x x x 0, y 0<0, f x 0, y 0 \text { adalah sebuah nilai maksimum lokal; } \\
\text { ii. } & \text { Jika } D>0 \text { dan } f x x x 0, y 0>0, f x 0, y 0 \text { adalah sebuah nilai minimum lokal; } \\
\text { iii. } & \text { Jika } D<0 \text { dan } f x 0, y 0 \text { bukan sebuah nilai ekstrem }(x 0, y 0 \text { adalah sebuah titik pelana }) \\
\text { iv. } & \text { Jika } D=0, \text { uji yang dilakukan tidak mempunyai hasil/tidak dapat disimpulkan. }
\end{array}
$$




\subsection{Metode Pengali Lagrange}

Andaikan akan dicari nilai ekstrem relatif fungsi dari $(X)$ dengan $n$ variabel dan $m$ kendala kesamaan seperti berikut:

Minimumkan $f(X)$

$$
\begin{array}{ll} 
& X=\left(x_{1}, x_{2}, \ldots, x_{n}\right) \\
\text { dengan kendala } & g_{j}(X)=0, j=1,2, \ldots, m
\end{array}
$$

Ada suatu ketentuan bahwa $m \leq n$, hal ini dikarenakan jika $m>n$ maka persamaan tersebut tidak bisa diselesaikan. Fungsi Lagrange $L$ untuk kasus ini didefinisikan dengan memperkenalkan pengali Lagrange $\lambda j$ untuk setiap kendala $g j(X)$ sebagai

$$
L\left(x_{1}, x_{2}, \ldots, x_{n}, \lambda_{1}, \lambda_{2}, \ldots, \lambda_{m}\right)=f(X)+\sum_{j=1}^{m} \lambda_{j} g_{j}\left(x_{1}, x_{2}, \ldots, x_{n}\right)
$$

Dengan memperlakukan $L$ sebagai sebuah fungsi $n+m$ variabel $x 1, x 2, \ldots, x n, \lambda 1, \lambda 2, \ldots, \lambda m$, maka syarat perlu untuk ekstrimum dari $L$ yang juga merupakan solusi masalah asal, diberikan oleh

$$
\begin{array}{ll}
\frac{\partial L}{\partial x_{i}}=\frac{\partial f}{\partial x_{i}}+\sum_{j=1}^{m} \lambda_{j} \frac{\partial g_{j}}{\partial x_{i}}=0, & i=1,2, \ldots, n \\
\frac{\partial L}{\partial \lambda_{j}}=g_{j}(X)=0, & j=1,2, \ldots, m
\end{array}
$$

Persamaan di atas melibatkan $n+m$ persamaan dalam $n+m$ variabel tak diketahui $x i$ dan . Penyelesaian dari persamaan di atas adalah $X *=(x *, x *, \ldots, x *) T$ dan $\lambda *=(\lambda *, \lambda *, \ldots, \lambda *) T$ (Djoko Luknanto, 2000).

\section{Pembahasan}

\subsection{Pengali Lagrange Dan Aplikasinya}

Pada bagian ini dianalisis karakteristik fungsi Lagrange yang dirujuk dari jurnal Lagrange Multiplier and their Application (Huijuan Li, 2008) dengan fungsi Lagrange dan teknik optimasi multivariabel dengan kendala persamaan yang mempunyai bentuk umum sebagai berikut:

dengan kendala:

$$
\phi(x, y, z, t)=0 \begin{aligned}
& u=f(x, y, z, t) \\
& \psi(x, y, z, t)=0
\end{aligned}
$$

Diberikan masalah dengan kendala optimasi seperti pada persamaan (9) maka fungsi Lagrange dari permasalahan di atas didefinisikan sebagai,

$$
L=f(x, y, z, t)-\lambda \phi(x, y, z, t)-\varpi \psi(x, y, z, t)
$$

dengan $\lambda$ dan adalah pengali Lagrange. 
Teorema :

Syarat perlu bagi sebuah fungsi $(x, y, z, t)$ dengan kendala $\phi x, y, z, t=0 \operatorname{dan} \psi x, y, z, t=0$, agar mempunyai minimum relatif adalah derivasi parsial pertama dari fungsi Lagrangenya yang didefinisikan sebagai $L x, y, z, t, \lambda, \mu$ $=(x, y, z, t, \lambda, \mu)$ terhadap variabel bebasnya adalah nol.

Bukti:

Diasumsikan bahwa di titik $(\xi, \eta, \zeta, \tau)$, fungsi $u$ akan mencapai nilai ekstrem ketika dicocokkan dengan nilai pada setiap titik tetangga yang memenuhi kendala. Terdapat 4 variabel dengan 2 persamaan kendala, sehingga terdapat 2 variabel bebas. Maka matriks Jacobbian $P$ dari persamaan kendala adalah

$$
\begin{aligned}
& \frac{\partial(\phi, \psi)}{\partial(z, t)}=\left|\begin{array}{ll}
\frac{\partial \phi}{\partial z} & \frac{\partial \phi}{\partial t} \\
\frac{\partial \psi}{\partial z} & \frac{\partial \psi}{\partial t}
\end{array}\right| \neq 0 \\
& \frac{\partial(\phi, \psi)}{\partial(z, t)}=\phi_{z} \psi_{t}-\phi_{t} \psi_{z} \neq 0
\end{aligned}
$$

Sehingga pada titik $P$ diketahui nilai 2 variabel yaitu $z$ dan $t$, seperti fungsi lainnya $x$ dan $y$. Subsitusi fungsi $z=$ $(x, y)$ dan $t=\mathrm{h}(x, y)$ ke fungsi objektif $u$, lalu diperoleh fungsi objektif dari 2 variabel bebas $x$ dan $y$, dan fungsi ini harus memiliki nilai ekstrem bebas pada titik $x=\xi, y=\eta$, sehingga memenuhi

$$
\begin{gathered}
f_{x}+f_{z} \frac{\partial z}{\partial x}+f_{t} \frac{\partial t}{\partial x}=0 \\
f_{y}+f_{z} \frac{\partial z}{\partial y}+f_{t} \frac{\partial t}{\partial y}=0
\end{gathered}
$$

Diambil turunan parsial terhadap $x$ diperoleh:

$\phi_{x}+\phi_{z} \frac{\partial z}{\partial x}+\phi_{t} \frac{\partial t}{\partial x}=0$
$\psi_{x}+\psi_{z} \frac{\partial z}{\partial x}+\psi_{t} \frac{\partial t}{\partial x}=0$

Dari persamaan (14) diperoleh bahwa:

$$
\begin{aligned}
& \frac{\partial z}{\partial x}=-\frac{\phi_{x}}{\phi_{z}}=-\frac{\frac{\partial \phi}{\partial x}}{\frac{\partial \phi}{\partial z}} \\
& \frac{\partial t}{\partial x}=-\frac{\psi_{x}}{\psi_{t}}=-\frac{\frac{\partial \psi}{\partial x}}{\frac{\partial \psi}{\partial t}}
\end{aligned}
$$


Jika persamaan (15) dan (16) disubsitusikan ke dalam persamaan (13) sehingga diperoleh:

$$
\begin{gathered}
f_{x}+f_{z} \frac{\partial z}{\partial x}+f_{t} \frac{\partial t}{\partial x}=0 \\
f_{x}-\frac{\partial f}{\partial z}\left(\frac{\partial \phi}{\partial x}: \frac{\partial \phi}{\partial z}\right)-\frac{\partial f}{\partial t}\left(\frac{\partial \psi}{\partial x}: \frac{\partial \psi}{\partial t}\right)=0 \\
f_{x}-\left(\frac{\partial f}{\partial z}: \frac{\partial \phi}{\partial z}\right) \frac{\partial \phi}{\partial x}-\left(\frac{\partial f}{\partial t}: \frac{\partial \psi}{\partial t}\right) \frac{\partial \psi}{\partial x}=0 \\
f_{x}-\lambda \frac{\partial \phi}{\partial x}-\nabla \frac{\partial \psi}{\partial x}=0
\end{gathered}
$$

Dengan demikian diperoleh: $f_{x}-\lambda \phi_{x}-\nabla \psi_{x}=0$

Secara serupa diperoleh: $\quad f_{y}-\lambda \phi_{y}-\varpi \psi_{y}=0$

Dari persamaan di atas pada penyelesaian optimum, perubahan fungsi tujuan $x, y, z, t$, berbanding lurus dengan perubahan kendala $\phi x, y, z, t$ dan $\psi x, y, z, t$ dengan faktor sebesar pengali Lagrange $\lambda$ dan $\mu$.

\subsection{Optimasi Berkendala Menggunakan Pengali Lagrange}

Pada bagian ini dianalisis karakteristik fungsi Lagrange yang dirujuk dari jurnal Constrained Optimization Using Lagrange Multipliers (Henri P. Gavin and Jeffrey T. Scruggs, 2016).Pada masalah dengan banyak variabel $(n \gg 1)$ dan banyak kendala pertidaksamaan $(m \gg 1)$, menentukan kendala pertidaksamaan yang akan digunakan pada titik optimum dapat menjadi sulit. Berikut adalah contoh optimasi berkendala dengan fungsi objektif kuadrat, dengan $n=$ 2 dan $m=2$.

$$
\min _{x_{1}, x_{2}} x_{1}^{2}+0.5 x_{1}+3 x_{1} x_{2}+5 x_{2}^{2}
$$

dengan kendala $3 x_{1}+2 x_{2}+2 \leq 0$

$$
15 x_{1}-3 x_{2}-1 \leq 0
$$

Dengan menggunakan metode pengali Lagrange, pengembangan fungsi objektif menjadi

$$
J_{A}\left(x_{1}, x_{2}, \lambda_{1}, \lambda_{2}\right)=x_{1}^{2}+0.5 x_{1}+3 x_{1} x_{2}+5 x_{2}^{2}+\lambda_{1}\left(3 x_{1}+2 x_{2}+2\right)+\lambda_{2}\left(15 x_{1}-3 x_{2}-1\right)
$$

Fungsi objektif di atas diturunkan secara parsial terhadap setiap variabel bebasnya, sehingga

$$
\begin{aligned}
& \left.\min _{x_{1}} J_{A} \Rightarrow \frac{\partial J_{A}}{\partial x_{1}}\right|_{x_{1}{ }^{*}, x_{2}{ }^{*}, \lambda_{1}{ }^{*}, \lambda_{2}{ }^{*}}=0 \Rightarrow 2 x_{1}^{*}+0,5+3 x_{2}^{*}+3 \lambda_{1}^{*}+15 \lambda_{2}^{*}=0 \\
& \left.\min _{x_{2}} J_{A} \Rightarrow \frac{\partial J_{A}}{\partial x_{2}}\right|_{x_{1}{ }^{*}, x_{2}{ }^{*}, \lambda_{1}{ }^{*}, \lambda_{2}{ }^{*}}=0 \Rightarrow 3 x_{1}^{*}+10 x_{2}^{*}+2 \lambda_{1}^{*}-3 \lambda_{2}^{*}=0 \\
& \left.\max _{\lambda_{1}} J_{A} \Rightarrow \frac{\partial J_{A}}{\partial \lambda_{1}}\right|_{x_{1}{ }^{*}, x_{2}{ }^{*}, \lambda_{1}{ }^{*}, \lambda_{2}{ }^{*}}=0 \Rightarrow 3 x_{1}^{*}+2 x_{2}^{*}+2=0 \\
& \left.\max _{\lambda_{2}} J_{A} \Rightarrow \frac{\partial J_{A}}{\partial \lambda_{2}}\right|_{x_{1}{ }^{*}, x_{2}{ }^{*}, \lambda_{1}{ }^{*}, \lambda_{2}{ }^{*}}=0 \Rightarrow 15 x_{1}^{*}-3 x_{2}^{*}-1=0
\end{aligned}
$$

- Pertama, tentukan minimum yang dibatasi oleh kendala $g 1(x 1, x 2)$ ataupun $g 2(x 1, x 2)$ yang aktif,

$$
\begin{aligned}
\lambda_{1}{ }^{*}= & 0, \lambda_{2}{ }^{*}=0 \text {, dan } \\
& {\left[\begin{array}{cc}
2 & 3 \\
3 & 10
\end{array}\right]\left[\begin{array}{l}
x_{1}{ }^{*} \\
x_{2}{ }^{*}
\end{array}\right]=\left[\begin{array}{c}
-0.5 \\
0
\end{array}\right] \quad\left[\begin{array}{l}
x_{1}{ }^{*} \\
x_{2}{ }^{*}
\end{array}\right]=\left[\begin{array}{c}
-0.45 \\
0.14
\end{array}\right] }
\end{aligned}
$$

Subsitusi nilai $x 1 *$ dan $x 2 *$ ke persamaan kendala. Sehingga nilai $g 1(x 1 *, x 2 *)=0.93$ dan $g 2(x 1 *, x 2 *)=-8.17$. Jadi, kendala $g 1$ tidak memenuhi persamaan kendala $g 1$ karena nilai kendala $g 1-0.45,0.14>0$.

- Selanjutnya, asumsikan kedua kendala $g 1(x 1, x 2)$ dan $g 2(x 1, x 2)$ adalah aktif, nilai optimal untuk $x 1 *, x 2 *, \lambda 1 *$, $\lambda 2 *$ dicari, dan keempat persamaan harus diselesaikan bersama-sama. 


$$
\left[\begin{array}{rrrc}
2 & 3 & 3 & 15 \\
3 & 10 & 2 & -3 \\
3 & 2 & 0 & 0 \\
15 & -3 & 0 & 0
\end{array}\right]\left[\begin{array}{l}
x_{1}^{*} \\
x_{2}{ }^{*} \\
\lambda_{1}{ }^{*} \\
\lambda_{2}{ }^{*}
\end{array}\right]=\left[\begin{array}{r}
-0.5 \\
0 \\
-2 \\
1
\end{array}\right]
$$$$
\left[\begin{array}{l}
x_{1}{ }^{*} \\
x_{2}^{*} \\
\lambda_{1}{ }^{*} \\
\lambda_{2}^{*}
\end{array}\right]=\left[\begin{array}{r}
-0.10 \\
-0.85 \\
3.55 \\
-0.56
\end{array}\right]
$$

Perhatikan bahwa $\lambda 2 *<0$ menunjukkan bahwa $g 2$ tidak aktif, dimana $2-0.10,-0.85=0$. Jadi, ketika solusi ini layak (baik $g 1$ dan $g 2$ menuju 0) solusinya bisa diperbaiki dengan melepaskan kendala $g 2$ dan bergerak ke garis $g 1$.

- Jadi, diasumsikan hanya kendala $g 1$ yang aktif, $g 2$ tidak aktif, $\lambda 2 *=0$, dan

$$
\left[\begin{array}{ccc}
2 & 3 & 3 \\
3 & 10 & 2 \\
3 & 2 & 0
\end{array}\right]\left[\begin{array}{l}
x_{1}{ }^{*} \\
x_{2} * \\
\lambda_{1} *
\end{array}\right]=\left[\begin{array}{c}
-0.5 \\
0 \\
-2
\end{array}\right] \quad \longrightarrow \quad\left[\begin{array}{l}
x_{1}{ }^{*} \\
x_{2}{ }^{*} \\
\lambda_{1}{ }^{*}
\end{array}\right]=\left[\begin{array}{c}
-0.81 \\
0.21 \\
0.16
\end{array}\right]
$$

Perhatikan bahwa $\lambda 1 *>0$ yang menunjukkan bahwa kendala ini aktif. Subsitusikan $x 1 *$ dan $x 2 *$ ke dalam $g 2 x 1$, $x 2$ memberikan nilai, $2-0.81,0.21=-13.78$. Jadi, kendala minimum ini layak dengan kedua kendala. Ini adalah solusi yang kita cari.

a. Sebagai pemeriksaan terakhir, diasumsikan hanya kendala $g 2$ yang aktif, $g 1$ tidak aktif, $\lambda 1 *=0$.

$$
\left[\begin{array}{ccc}
2 & 3 & 15 \\
3 & 10 & -3 \\
15 & -3 & 0
\end{array}\right]\left[\begin{array}{l}
x_{1}{ }^{*} \\
x_{2}{ }^{*} \\
\lambda_{2}{ }^{*}
\end{array}\right]=\left[\begin{array}{c}
-0.5 \\
0 \\
1
\end{array}\right] \quad \Rightarrow \quad\left[\begin{array}{l}
x_{1}{ }^{*} \\
x_{2}{ }^{*} \\
\lambda_{2}{ }^{*}
\end{array}\right]=\left[\begin{array}{c}
0.06 \\
-0.03 \\
-0.04
\end{array}\right]
$$

Perhatikan bahwa $\lambda 2 *<0$, yang menunjukkan bahwa kendala tidak aktif, bertentangan dengan asumsi kita. Selanjutnya, subsitusi $x 1 *$ dan $x 2 *$ ke dalam $g 1(x 1 *, x 2 *)=2.12$. Sehingga kendala minimum ini tidak cocok dengan kendala $g 1$ karena $g 10.06,-0.03>0$. Dari hasil di atas diperoleh bahwa titik kritis fungsi $J A x 1, x 2, \lambda 1, \lambda 2$ adalah ($0.81,0.21,0.16,0)$, sehingga nilai ekstrem dari $J A x 1, x 2, \lambda 1, \lambda 2$ adalah -0.0403 .

\section{Kesimpulan}

Berdasarkan kajian dan analisis yang dilakukan dapat disimpulkan bahwa karakteristik dari metode Lagrange adalah kemampuan mentransformasikan permasalahan optimasi berkendala menjadi permasalahan optimasi tanpa kendala.Metode pengali Lagrange mampu menyelesaikan masalah optimasi dengan fungsi nonlinier. Selain itu metode ini mampu menyelesaikan masalah dengan kendala persamaan dan pertidaksamaan. Tetapi dalam penyelesaiannya, metode Lagrange tidak menjamin akan dihasilkan solusi optimum global, karena fungsi kendala yang aktif adalah fungsi kendala yang memenuhi nilai dari persamaan kendala.Metode pengali Lagrange menyediakan suatu metode aljabar untuk menentukan titik kritis, sehingga masalah ekstrem berkendala dapat diatasi, dimana perubahan fungsi tujuan berbanding lurus dengan perubahan kendala dengan faktor sebesar pengali Lagrange.

\section{Referensi}

[1] Gavin, H.P and Jeffrey T.S. 2016. Constrained Optimization Using Lagrange Multipliers. https://math.berkeley.edu. [19 April 2016].

[2] Li, H. 2008. Lagrange Multipliers And Their Applications. http://sces.phys.utk.edu. [03 Juni 2016]

[3] Luknanto, D. 2000. Pengantar Optimasi Non-Linier.http://luk.staff.ugm.ac.id. [15 Maret 2016]

[4] Moengin, P. 2011. Metode Optimasi. Bandung: CV. Muara Indah.

[5] Purcell, E.J., Dale, V., and Steven, E.R. 2003. Calculus Eighth Edition Varberg, Purcell, Ringdon. Jakarta: Erlangga. 